\title{
Don Segundo Sombra: Una Novela Monológica
}

\section{INTRODUCCION}

Transcurrido medio siglo de la publicación de Don Segundo Sombra ${ }^{1}$ (1926), se hace necesaria una revisión crítica de la novela, bajo la luz de los conceptos. modernos de la lingüística y teoría literaria. Estos elementos nos ayudarán a revelar significados subyacentes, que una lectura lineal normalmente encubre, al enmascarar ideologías latentes en el texto. La operación crítica de la obra nos ubicará inicialmente fuera del texto, para pasar, posteriormente, a una etapa de penetración analítica. Una vez realizada la integración de los elementos críticos en los analíticos, pasaremos a una evaluación final de la obra, de cuño ideológico.

La época de Ricardo Güiraldes es la de la posguerra europea, y se caracteriza por los movimientos de vanguardia que niegan los valores burgueses, seguros y estables: "enfrentemos la locura", pregona André Breton, revelando un ansia incontrolable donde predomina la aventura, lo heroico y lo instintivo por sobre lo racional. Estas preocupaciones coinciden con el pensamiento de los años 20, que aspira al nacionalismo, un lenguaje propio, una imagen caracterizadora, en fin, una identidad propia. Estas tendencias van a desembocar en la Argentina-por un lado en los movimientos literarios urbancs de Florida y Boedo, y por otro en la revaloración de los héroes criollistas como Santos Vega, Martín Fierro y posteriormente Don Segundo Sombra.

Esbozaremos inicialmente una imagen del gaucho compatible con su realidad primera (extra-textual), lo que servirá como punto de referencia para evaluar posteriormente la manipulación artística del material tratado por Ricardo Güiraldes. Si en relación a México y Perú se puede hablar de una

\footnotetext{
${ }^{1}$ Ricardo Güiraldes, Don Segundo Sombra (Buenos Aires: Losada, ed. original de 1926). De ahora en adelante adoptaremos la siguiente sigla para denominar la obra: $D S S$.
} 
"transfusión cultural", entre las razas dominadoras y las dominadas, ya en regiones ajenas a estas civilizaciones hubo un verdadero transplante de cultura, logrado a través de la imposición a los indios del catolicismo y de la lengua española, que se convirtieron en vehículos culturales y soporte del colonialismo. En Argentina los conquistadores sólo encontraron tribus nómades de indios sin ninguna sedimentación cultural que pudiese contaminar la fuerza impositiva de los españoles. La confluencia de tres razas: la india, la negra y la europea dio origen a lo que puede ser definido como lo más originalmente ríoplatense: el gaucho. Inevitablemente surgiría el conflicto de identidad que en el proceso de cruce racial provocaría tensiones de definición étnica en dirección a alguna de las tres razas predominantes; observa irónicamente Uslar Pietri:

Hubo quienes trataron con todas las fuerzas de su alma de parecer franceses, ingleses y americanos del norte. Hubo más tarde quienes se creyeron indígenas y se dieron a reivindicar la plenitud de una civilización aborigen irrevocablemente interrumpida por la Conquista, y no faltaron tampoco, en ciertas regiones, quienes se sintieron posesos de un alma negra y trataron de resucitar un pasado africano. Culturalmente no eran europeos, ni mucho menos podían ser indios o africanos. ${ }^{3}$

Comienza así a delinearse 'un producto humano original en el Nuevo Mundo, prácticamente bifurcado: por un lado el hombre aristocrático y europeizante (pero culturalmente mestizo), hasta el nacimiento de la burguesía ascendiente de los siglos XIX y XX, y por otro lado el producto regionalista, el hombre que convive con la naturaleza. En la Argentina este hombre de la tierra surge sintetizado en la figura del gaucho. ${ }^{4}$

${ }^{2}$ Ernesto Sábato, La cultura en la encrucijada nacional (Buenos Aires: Crisis, 1973). El concepto de "transfusión cultural" ya fue magistralmente expuesto por Arturo Uslar Pietri a través de la noción de "mestizaje cultural". Estos conceptos coinciden en una visión contaminadora de culturas.

"Arturo Uslar Pietri, "El Mestizaje y el Nuevo Mundo", en En Busca del Nuevo Mundo (México: F.C.E., 1969).

${ }^{4}$ La definición histórico-etimológica del gaucho ha sucitado graves controversias entre los estudiosos del tema. Por un lado se encuentran todos aquellos que atribuyen al origen de la existencia del gaucho una carga altamente peyorativa que va a identificarlo con el malevaje, nomadismo, robo, etc. La mayor parte de la documentación exprime la ideología extranjera, urbana y del poder. Por otro lado (Fernando Assunção, A.M. Carretero, A.J.P. Amuchástegui, etc.) se encuentran aquellos historiadores que le reivindican al gaucho una posición socioeconómica determinada: trabajadores altamente asalariados en la industria del cuero, carne, etc., más específicamente aquellos gauchos de la Banda Oriental del Uruguay. Las consecuencias literarias llegan hasta nuestros días. Afirma Borges en Posdata de 1974: "El Martín Fierro es un libro muy bien escrito y mal leído. Hernández lo escribió para mostrar que el Ministerio de Guerra - uso la nomenclatura de la época-hacía del gaucho un desertor y un traidor; Lugones exaltó ese desventurado a paladín y lo propuso como arquetipo. Ahora padecemos las consecuencias" ("Hernández: Martín Fierro" (En Prólogos, Buenos Aires: Torres Agüero Editor, 1975, p. 99).

Una excelente sistematizacion y planteamiento de estas posiciones antagónicas se encuentran en el "Estudio Preliminar" de Beatriz Bosch, a la obra de Emilio A. Coni, El Gaucho (Buenos Aires: Hachette, 1969 , pp. 7-21). Ella define el problema como siendo "uno de los más apasionantes enigmas de nuestra historia", y todas las perspectivas son unánimes en atribuir al alambrado la causa de la muerte histórica del gaucho. 
La mímesis literaria capta la realidad gauchesca en sus más diversos aspectos. En poesía, y como proyección de la tradición oral de la 'payada', encontramos tres grandes obras poéticas: Santos $\mid$ Vega, de Hilario Ascasubi(1872), Fausto, de Estanislao del Campo (1866), y Martín Fierro de José Hernández (1872), que se convierte en el más importante de los poemas 'épicos, no sólo por su estructura poética, sino por la visión despojada y desmistificadora del gaucho. En prosa, la primera obra más importante es Facundo de Domingo Faustino Sarmiento (1845), que funda el famoso binomio "civilización vs. barbarie", y nos ofrece una perspectiva diametralmente opuesta al segundo clásico de la prosa gauchesca: Don Segundo Sombra.

Independientemente del tratamiento formal dado a la narrativa, y de la relación hombre/naturaleza, encontramos en estas obras un denominador común que es la búsqueda de un lenguaje propio que les dará originalidad y representará en el relato el rasgo diferencial en relación a las literaturas europeas, de quienes dependen en cuanto a técnicas narrativas.

\section{DSS Y EL GENERO}

Es necesario aún caracterizar la obra de acuerdo a su género, ya que esto posibilita dimensionarla en su tiempo específico. La novela adquiere universalidad al ser integrada al género al cual pertenece, de dos modos: por los rasgos de analogía con las otras obras, lo que ayuda a categorizarla, y por los rasgos diferenciales que la tornan peculiar y única en relación al resto, de las cuales se distingue. Si un análisis específico e inmanente de la novela es permisible (como lo han hecho los New Critics y los estructuralistas franceses), esto puede llegar a ser reductivo como método al aislarla de su contexto-o sea, su tiempo y lugar históricos.

\subsection{DSS y el Realismo/Naturalismo}

La ficción realista desempeña una función mimética del medio circundante y retrata una perspectiva de lo cotidiano que se opone, en DSS, a la visión idealizada del héroe. Este enfoque denota una participación intensa y altamente subjetiva por parte del narrador, oponiéndose así a la descripción objetiva del narrador realista. De este modo encontramos en $D S S$ la búsqueda de una verdad representativa de la realidad concreta del gaucho, pero ésta es inverosímil en relación a su referente extralingüístico, ya que hace de él más un tipo genérico que un individuo concreto. Pero la técnica altamente descriptiva del campo así como el ansia por el detalle (lo que la hace predominantemente metonímica), no niegan totalmente una técnica realista en el retrato de la naturaleza.

Esto permitiría encuadrar la obra dentro de los cánones del naturalismo, ya que, como es sabido, la obra naturalista se caracteriza por la técnica realista de descripción así como por el amor intenso a la naturaleza. Pero filosóficamente (por ejemplo, en $\mathrm{H}$. Taine) el naturalismo otorga a la naturaleza una función modificadora del hombre y es determinante de un proceso histórico. Así, a pesar del papel preponderante que la naturaleza ocupa en la descripción de $D S S$, ella no se caracteriza como fuerza 
modificadora y opositora del desempeño del héroe. La relación hombre/naturaleza es de manifestación muy diversa: en vez de constituirse en una relación dialéctica donde el sujeto modifica al objeto, o viceversa, se establece una verdadera ecuación de igualdad, donde la clásica oposición sarmientina "civilización vs. barbarie" queda reducida a una relación de identificación o extensión. Al describir al gaucho, afirma el narrador: "Tenían alma de reseros, que es tener alma de horizonte" (p. 43); esta definición del gaucho es integrante de la relación hombre/contexto, en nuestro caso, gaucho/pampa. Este proceso de síntesis se universaliza en la medida en que otros elementos de la natúraleza pasan por un proceso análogo de identificación con el hombre: "Animales y gente se movían como captados por una idea fija: caminar, caminar, caminar" (p. 51). Vemos así unificados en un mismo proceso, el hombre y el animal. No sólo las acciones de los dos se igualan, sino también sus sentimientos:

A las diez el pellejo de la espalda me daba una sensación de efervescencia. El petiso tenía sudado el cogote. La tierra sonaba más fuerte bajo las pezuñas siempre livianas.

A las once tenía hinchadas las manos y las venas. Los pies me parecían dormidos. Dolíanme el hombro y la cadera golpeados. Los novillos marchaban más pesadamente. El pulso me latía en las sienes de manera embrutecedora. A mi lado la sombra del petiso disminuía desesperadamente despacio. (p. 51)

Se configuran inicialmente dos entidades que, unidas en un mismo recorrido, desempeñando las mismas acciones y caracterizados por los mismos atributos, acaban convirtiéndose en una única entidad, un único paradigma. Diluída cualquier posibilidad de determinismo de la naturaleza en relación al hombre, se desdibujan las posibilidades de encuadrar la obra dentro de los moldes naturalistas.

\subsection{DSS y el Regionalismo}

Resta comprobar si podemos caracterizar la obra en cuestión dentro del movimiento regionalista, ya que la novela ofrece una minuciosa descripción de la pampa, enriquecida por el profundo conocimiento de las costumbres de esa región argentina. Estos datos serían más que suficientes para clasificarla como novela regionalista, si dicho movimiento no fuese considerado como de 'vuelta a la tierra', en el sentido de oposición al industrialismo, e inclusive al naturalismo. No sólo no hay en esta novela oposición al industrialismo, como desde el punto de vista social no hay oposición de ninguna especie. Es así como en los últimos capítulos (XXVI y XXVIII) el héroe/gaucho Fabio Cáceres se asocia a Raucho (representante del dueño de la tierra), realizando el primero una metamorfosis de los valores del segundo:

Raucho me dio los primeros galopes a unos bayos que me regaló para entablar la tan deseada tropilla de ese pelo. Yo le correspondí de igual modo y en igual cantidad con unos alazanes. Mutuamente nos servimos de padrinos durante la amansadura. Nuestro compañerismo, por cierto, 
no podía haberse cimentado mejor, ni de modo más gaucho. Para dos muchachones que andaban a caballo de sol a sol, era una forma de esta.r siempre presentes el uno para el otro. (p. 183)

Después que nuestro héroe Fabio Cáceres pasa a adquirir 'status' social análogo al de Raucho a través del intercambio de objetos, nos sorprende al revelar que: "A mi andar cotidiano sumaba mis primeras inquietudes literarias (...) que fueron transformándome exteriormente en lo que se llama un hombre culto" ( $p$. 184). Este brusco cambio de personalidad surge después que Fabio Cáceres lo ve a Raucho como un hombre que "sabía una barbaridad en cuanto a lecturas y libros" (p. 183). Así como el narrador/protagonista mimetizó inicialmente a su héroe Don Segundo, de la misma manera asume con plenitud su nuevo 'status' social al final de la novela. Esta ausencia de tensiones hace que no se operen modificaciones sociales, tornando la narrativa altamente lineal y descriptiva.

Otro factor que impide caracterizar a $D S S$ como obra regionalista por excelencia, es la posición del narrador, que tradicionalmente adopta en dichas obras la "visión desde afuera". Güiraldes narra en primera persona, lo que representa una importante innovación como técnica narrativa, sea para su época como para ese género novelístico.

Vemos como la obra huye en sus varios aspectos a una definición radical genérica, y se advierte en los diversos críticos una dificultad de categorizar a $D S S$, aunque la preferencia recaiga evidentemente en la linea del regionalismo. La solución encontrada por Arturo Torres Ríoseco, en su Nueva Historia de la Gran Literatura Iberoamericana fue abrir un capítulo aparte para la literatura gauchesca. Una antología de textos ${ }^{5}$ lega a incluir a DSS dentro del movimiento de la prosa modernista - tal vez por la riqueza estilística lograda en la descripción de la naturaleza. La aproximación más pertinente, en función de una categorización del género, es, eventualmente, aquella emitida por José Miguel Oviedo, cuando define a DSS como una "superación del criollismo ríoplatense", o sea, una obra regionalista que se diferencia de las demás por el "tratamiento hiperartístico de la realidad". 6

\section{DON SEGUNDO VERSUS MARTIN FIERRO}

Trataremos de analizar lo que se entiende por un "tratamiento hiperartístico de la realidad". En primer lugar la novela posee un soporte concreto que es su elemento referencial, o sea, el medio ambiente retratado y que aspira, en el caso de DSS a una fidelidad mimética. No es que el análisis trate de investigar las relaciones de compatibilidad entre los elementos del binomio ficción/realidad, sino que debemos tener una noción precisa del material extralingüístico, para poder relativizarlo durante nuestra lectura. Para eso confrontaremos DSS con Martín Fierro. ${ }^{7}$ José Hernández afirma, en la carta introductoria, con respecto

${ }^{5}$ Alfredo Veiravé, Literatura Hispanoamericana (Buenos Aires: Kapelusz, 1973).

"6. José Miguel Oviedo, "Una discusión permanente", (En América Latina en su literatura (México: Siglo XXI, 1972, p. 424).

${ }^{17}$ José Hernández, Martín Fierro (Buenos Aires: Losada, 1958). 
del gaucho: "los abusos y todas las desgracias de que es víctima esa clase desheredada de nuestro país". Se entiende por "clase desheredada" un grupo sin identidad y sin derechos. En realidad el gaucho fue usado en la segunda mitad del siglo XIX para perseguir al indio y cuidar las fronteras:

Nos anunciaban que iríamos

sin carretas ni bagajes

a golpiar a los salvajes

en sus mesmas tolderias (v. 942-945)

así como es usado para votar: "porque el gaucho en esta tierra/sólo sirve pa votar" (v. 1371-2), y afirma como conclusión:

El anda siempre juyendo

siempre pobre y perseguido;

no tiene cueva ni nido,

como si fuera maldito;

porque el ser gaucho...barajo!

el ser gaucho es un delito (v. 1320-5)

José Hernández propone, a través de Martín Fierro, revelarle al lector una realidad cruel, imbricada en pura forma poética como proyección de la payada. Vemos entonces al gaucho como una clase perseguida, sin posesiones y utilizada para las necesidades inmediatas de los gobiernos. El desprecio por su figura es notable en esa época: "...hay que recordar que antes de 1916 (fecha de $E l$ Payador, de Lugones) el gaucho no es el símbolo de la nacionalidad argentina; es, más bien, el símbolo de la barbarie que la nueva orgullosa nación quiso no sólo erradicar sino obliterar por el olvido (...) para la gente pudiente de entonces, el gaucho representaba la ralea, la barbarie, las masas armadas que tanto podían servir para una causa justa (la Independencia) como para ponerse al servicio de estancieros bárbaros y ambiciosos (como Rosas y los demás caudillos)...", afirma Emir Rodríguez Monegal, ${ }^{8}$ y en la década del 20 el gaucho es un tipo en extinción (hoy hasta la payada, como tradición oral, ha desaparecido). Es importante realizar el hecho de que más de medio siglo transcurre entre un libro y otro, y DSS es la primera obra que le dará altura y condición mítica, hasta convertir al gaucho en una leyenda. Para esto fue necesario el alejamiento geográfico (Güiraldes vivió muchos años alejado de la Argentina), y la distancia temporal.

Güiraldes jamás reconoce al gaucho como una figura perseguida, y justifica su continuo andar como parte inherente de su personalidad. La misma dedicatoria nos da índices de la dimensión legendaria y sagrada que el gaucho asume para el autor: "Al gaucho que llevo en mí, sacramente, como la custodia lleva la hostia", y al inicio de la novela Don Segundo es definido como siendo "más una idea que un ser", idea ésta que se proyecta a través de la obra, y surge

\footnotetext{
${ }^{8}$ Emir Rodríguez Monegal, "El Martín Fierro en Borges y Martínez Estrada" (En Revista. Iberoamericana, vol. XL, Abril-Septiembre de 1964, Núms. 87-88, pp. 289-290). Véase también, en el mismo vol. (pp. 219-230) el artículo de Alfredo Roggiano, "Destino personal y destino nacional en el Martin Fierro, donde se estudia la obra en el proceso histórico de la Argentina dentro del marco, más amplio, de la cultura europea.
} 
nuevamente al final: "Aquello que se alejaba era más una idea que un hombre". Vemos cómo se instaura una sólida relación binaria: ser terrenal/ser idealizado, concreto/abstracto, real/mítico, sólo que en vez de haber una relación de oposición, existe un proceso de proyección de un elemento sobre el otro. El proceso es no-disyuntivo, o sea, trata de conciliar los dos extremos.

La impasibilidad del gaucho, elemento mostrado con bastante insistencia, es un medio de tornarlo menos humano, y agrandarlo como personaje. Describiendo la reacción de Don Segundo, nos dice el narrador/protagonista:

No pudimos contener la risa, malgrado el asombro que nos causaba esta tranquilidad que llegaba a la inconsciencia. De golpe el forastero Don Segundo volvió a crecer en mi imaginación, (p. 20; lo subrayado es mío) y más tarde, relata la caracterización irónica que el paisanaje hace de Don Segundo:

Ahora lo tasaban detallando su estatura, la reciedumbre de sus rasgos y, sobre todo, esa tranquilidad con que sabía tomar las cosas, fueran como fuesen, como si le quedaran chicas. (p. 104)

La visión agrandada y magnificada se repite constantemente, y el hecho de que Don Segundo, desde el punto de vista de su participación, sea un personaje secundario (a pesar de que la novela lleva su nombre), es un medio de exponerlo menos y mantener su áurea mítica constantemente. La reducida participación verbal de Don Segundo se justifica por el mismo motivo, y cuando lo hace en extensión, es para contar los dos relatos: "Historia de Dolores y Consuelo"' (cap. XII) e "Historia de Miseria" (cap. XXI). Don Segundo se esconde detrás de sus propios relatos, que enriquecen la temática del folklore gauchesco, pero no ponen en evidencia a Don Segundo como personaje en ningún momento. El acto de narrar es utilizado como instrumento legendario, o sea, no individualiza al personaje sino que lo mitifica al insertarlo en la tradición comunitaria. La grandeza de Don Segundo es siempre retratada por la voz del narrador/ protagonista, así como por otros personajes secundarios; pocas veces a través de sus acciones, en contraste con la esfera de acción de Fabio Cáceres, que en última instancia es una tentativa de imitación de Don Segundo:

Cinco años de esos hacen de un chico un gaucho, cuando se ha tenido la suerte de vivirlos al lado de un hombre como el que yo llamaba mi padrino. El fue quien me guió pacientemente hacia todos los conocimientos de hombre de pampa. El me enseñó los saberes del resero... (p. 63)

\subsection{Criticas "Sombristas" Versus Críticas "Fierristas"}

Este modelo de gaucho sigue, en rigor, un comportamiento de características "machistas". La más notable de ellas no es exteriorizar los sen. timientos, como fue visto a través de la impasibilidad e introversión de las emociones. Fabio Cáceres, al tratar de mostrar sus emociones, confiesa: 
Me dominóla|rudeza de aquellos tipos callados, y no sé si por timidez o por respeto, dejé caer la barbilla sobre el pecho, encerrando asi mi emoción. (p. 43; lo subrayado es mío)

En el momento de la separación final, Don Segundo se reprime y justifica su actitud afirmando que "tristeza era cobardía". Vemos como la obra aparece filtrada por una filosofía en la cual 'a golpes se hace el hombre'.

Este comportamiento rudo se justifica en la relación medio/hombre, ya que la pampa, como espacio inmenso, vacío y sin estímulos, acaba provocando la introspección del personaje. Ernesto Sábato define al gaucho de esta manera:

(...) así como las tres religiones occidentales surgieron en solitarios hombres enfrentados con el desierto, en nuestro país comenzó a desarrollarse ese temperamento meditativo que tipificaría luego el gaucho de nuestra etapa, en medio de esa metáfora de la Nada y de lo Absoluto que es la llanura sin límites ni atributos. ${ }^{10}$

Con esta visión magnificada del gaucho pactan quienes analizaron a DSS desde el punto de vista estilístico y se preocuparon con los aspectos formales de la narrativa elevándola a la categoria de obra cumbre: fue ésta la visión de Amado Alonso, José Miguel Oviedo, Raúl Castagnino, Ernesto Sábato y casi sin excepción todos los críticos de la época en que la obra fue lanzada. Ya aquellos críticos que se preocuparon más por los elementos referenciales extratextuales, desmerecen la obra por no ser compatible con la realidad inmediata que intenta retratar, y ven así a Don Segundo como una entidad ubicada fuera de los cánones temporales. Esta antinomia crítica es tan vieja como la propia novela; ya en 1935, Leopoldo Marechal, ensalzando el valor de la "obra pura", hace una síntesis de las dualidades críticas en relación a DSS:

(...los críticos vacilan: "Don Segundo'Sombra", ¿seráo no el arquetipo de nuestro paisano? Algunos admiten que lo es, y tras una lamentación de su miseria presente lo señalan como sujeto de las futuras reivindicaciones; otros le niegan verosimilitud, y el pobre "Don Segundo" aparece entonces como un paisano irreal, adaptado al gusto de la mitología gauchesca. No faltan los mal intencionados que ven en la obra una creación interesada de Güiraldes: para ellos "Don Segundo" es el gaucho visto por el patrón, el explotado visto por el que lo explota, conclusión maligna que huele a "viento libertario" y que se funda no en un juicio, sino en un prejuicio.

Fue Paul Groussac, contemporáneo de Güiraldes, quien, en una brillante

\footnotetext{
${ }^{9}$ Esta perspectiva expresa, coincidentemente, la ideología del propio autor; confiesa éste en carta enviada a Victoria Ocampo en agosto de 1917: "Mi orgullo de gaucho siempre me dijo que el macho no llora", en la revista Sur(Buenos Aires, 1931, no. 1, p. 102).

${ }^{10}$ Ernesto Sábato, op. cit., p. 80.

${ }^{11}$ Leopoldo Marechal, "Don Segundo Sombra y el ejercicio ilegal de la crítica" (En revista Sur, no. 12 , septiembre de 1935 , pp. $76-77$ ).
} 
metáfora manifiesta su rechazo al texto por el intento fracasado de disfrazar la evidencia histórica:

un libro cimarrón, escrito por un hombre de buena sociedad; a través del chiripá se le ve el smocking.

También Ciro Alegría afirmó que la perfección de $D S S$ no sufrió un proceso que envolvió conflictos, sino por el contrario, ella es arbitraria. Por eso, afirma el autor, "lo que se trata precisamente en la novela es de que la idea se haga ser, de que el personaje sea ser. No es preciso deshumanizarlo para que represente algo. Por el contrario, debe representar algo humanamente"."

Para finalizar el retrato del gaucho, mencionaremos el problema de su identidad, ya que ella no es cuestionada en el sentido racial de confluencia de culturas, y menos aún en el proceso de identificación individual del héroe, para quien gaucho es igual a guacho. Lo gauchesco es visto como un hecho consumado, y no como el fruto temporal, consecuente del cruce de varias culturas.

Un primer momento de crisis de identidad individual, no volcado hacia lo gauchesco sino al problema de su origen familiar, lo encontramos al comienzo de la novela:

¿Mi casa? ¿Mis tías? ¿Mi protector Fabio Cáceres? Por centésima vez aquellas preguntas se formulaban en mi, con grande interrogante ansioso, y por centésima vez reconstruí mi breve vida como única contestación posible, sabiendo que nada ganaría con ello; pero era una obsesión tenaz. (p. 11)

Este cuestionar tiene por función causar el dislocamiento geográfico de Fabio Cáceres, o sea, la salida de su casa para seguir a Don Segundo. Es el único momento de opción del personaje en la novela, que lo caracteriza como individuo, y lo ayuda posteriormente a definirse en todo aquello que se entiende por 'gauchesco'. Un segundo momento de crisis (ya de orden social), es cuando, al final de la novela, el héroe se ve repentinamente dueño de una herencia, y no sabe qué hacer con ella. Pero esta crisis no cambia el rumbo de las cosas, pues según el propio Don Segundo, quien nace gaucho muere gaucho: "Si sos gaucho en de veras, no has de mudar, porque andequiera que vayas, irás con tu alma por delante como madrina'e tropilla" (p. 176).

Lo gauchesco es mostrado como una entidad cristalizada, carente de un proceso histórico, inherente a todo grupo social. Ya se ha definido al gaucho como protagonista de "la angustia ontológica del criollo, que desde hace cuatro siglos se pregunta incesantemente, sin hallar respuesta definitiva: iquien soy? ¿cuál es mi destino?". Ésta es la pregunta que Don Segundo Sombra no se formula. Tal vez por esta distancia de la imagen real del gaucho, fue necesario

\footnotetext{
${ }^{12}$ cf. Antonio Pagés Larraya, "Don Segundo Sombra y el retorno" (En Cuadernos , Hispanoamericanos, Madrid, Agosto-Septiembre 1962, no. 152-153, p. 282).

${ }^{13}$ Ciro Alegría, "Notas sobre el personaje en la novela hispanoamericana" (En Juan Loveluck, La novela hispanoamericana, (Santiago, Chile: Editorial Universitaria, 1969, pp.121-122).
} 
crearle una perspectiva idealizada, mítica. La imagen concreta, real entraría en contradicción con la visión benevolente y utópica que el autor diseña del personaje y su mundo.

\section{DON SEGUNDO Y FABIO CACERES: EL PERSONAJE ESTATICO}

Debemos establecer aún qué tipo de personajes son Don Segundo y Fabio Cáceres. Podemos considerar a los dos como un binomio, ya que uno es la proyección del otro, como fue visto. Si adoptamos los criterios de E. M. Forster (Aspects of the Novel), estariamos inclinados a definir a Don Segundo como personaje "plano", ya que la obra propone un héroe arquetípico, sintetizador ideal de todas las cualidades de un gaucho. Don Segundo no muestra en ningún momento riqueza interior ("densidad psicológica") y Fabio Cáceres, a pesar de narrar en primera persona (lo cual sería altamente propicio para el conocimiento interior del personaje), tampoco se revela "redondo". En vez de cambios, hay una acumulación de experiencias; el aprendizaje del héroe no se da como el resultado de una dialéctica interna de la personalidad (como sería el caso de Hamlet, donde el yo que conversa consigo mismo se angustia, elucida dudas, etc.) Lo que existe es un proceso asimilatorio de experiencias en un movimiento que se produce de afuera hacia adentro y que va configurando al héroe como tal. El único momento de cambio, que se puede afirmar que sea de adentro para afuera, es la opción de Fabio Cáceres como individuo durante el primer capitulo, al seguir a Don Segundo; pero en último análisis, esta opción es también fruto de un estímulo externo (el propio Don Segundo), que acompaña al héroe hasta su delineamiento final como gaucho. El cambio final, de ascención social, tampoco es consecuencia de tensión entre la clase gaucha y la terrateniente: hay una herencia (de afuera hacia adentro) y una verdadera simbiosis de los valores de aquellos que poseen la tierra.

Otra posibilidad de caracterizar al personaje es a través de sus acciones (y no sólo por sus atributos), visión calificativa, para la cual apuntan los 'tipos' creados por Forster. No es suficiente saber cómo es el personaje, sino qué es lo que hace, a quién modifica, y, a su vez, por quién es modificado. Tendríamos así una visión más dinámica del personaje, en relación con el mundo que lo circunda, del cual es imposible abstraerse, ya que este mundo representa el contexto que lo configura. Entraríamos así en las esferas de acción y no apenas en la de los atributos; esto representaría una visión funcional del héroe: "Entendemos por función la acción de un personaje, definida desde el punto de vista de su significación en el desarrollo de la intriga", afirma Vladimir Propp. ${ }^{14}$ Estamos delante de una propuesta de análisis que se define dialécticamente a través de las acciones del personaje.

¿De qué manera es aplicable este modelo a $D S S$ y en qué medida una visión de las acciones del héroe puede ayudarnos en el proceso de deslinde de la obra? Para esto, debemos formularnos una primera pregunta: ¿Cuál es el objeto de las

${ }^{14}$ Vladimir Propp, Morphologie du conte (Paris: Seuil, 1965), p. 31 (traducción mía). 
acciones de Fabio Cáceres?: ser igual a Don Segundo, como ya fue explicado. El verbo adecuado para el desempeño de una acción es hacer, y no ser; esto caracteriza a Fabio Cáceres más como héroe ontológico que como personaje capaz de desempeñar acciones. Si la visión de Don Segundo es idealizada, es porque pertenece al mundo del mito, y este universo es, desde el punto de vista de la acción, totalmente estático. Veamos dos ejemplos concretos, que aclaran el universo de las acciones de Don Segundo:

a. Pero por sobre todo y contra todo, Don Segundo queria su libertad. Era un espíritu anárquico y solitario, a quien la sociedad continuada de los hombres concluía por infligir un invariable cansancio. Como acción, amaba sobre todo el andar perpetuo; como conversación, el soliloquio. (p. 64; lo subrayada es mío)

b. Animales y gente se movían como captados por una idea fija: caminar, caminar, caminar.' (p. 51)

Abstrayendo, encontramos dos deseos bien nítidos:

a. deseo de libertad (nivel abstracto)

b. deseo de caminar (nivel concreto)

Sólo que el concepto de libertad, para el universo ideológico de $D S S$ (en última instancia el de Ricardo Güiraldes), no nos lleva a una visión dinámica de la novela. Libertad: ¿verse libre de qué o de quién? Es una visión romántica de la libertad, de desarraigo, de ausencia total de posesiones que se manifiesta a nivel de la conciencia o de la voluntad dirigida del personaje:

¡Mis heredades! Podía mirar alrededor, en redondo, y decirme que todo era mío. Esas palabras nada querían decir. ¿Cuándo en mi vida de gaucho, pensé andar por campos ajenos? ¿Quién es más dueño de la pampa que un resero? Me sugería una sonrisa el solo hecho de pensar en tantos dueños de estancia, metidos en sus casas, corridos siempre por el frío o por el calor, asustados por cualquier peligro que les impusiera un caballo arisco, un toro embravecido o una tormenta de viento fuerte. ¿Dueños de qué? Algunos parches de campo figurarían como suyos en los planos, pero la pampa de Dios había sido bien mía, pues sus cosas me fueron amigas por derecho de fuerza y baquía. (p. 182)

La noción burguesa de libertad está justamente fundamentada en la acumulación de capital y consecuente poder, lo que posibilita al hombre, dentro del sistema, liberarse como fuerza dominadora, ya que puede establecer los límites de esta libertad; diametralmente opuesta, la clase dominada "disfruta" de su libertad, de acuerdo a los límites impuestos. La definición de libertad aparece en DSS estrechamente relacionada con la noción de posesiones, ya que Ricardo Güiraldes ecuaciona el concepto de libertad como ausencia de posesiones. Así, el ideal de libertad de Don Segundo es no poseer ni ser poseido, coherente con la visión 
mítica del personaje. Es un concepto de libertad totalmente ausente de tensiones sociales que se reflejen en el individuo, o vice-versa.

Si el deseo de libertad en $D S S$ es una noción abstracta, el deseo de acción más concreto es el acto de caminar. Pero es un caminar que se iguala a un no caminar: desde el punto de vista espacial, el héroe regresa a su punto de partida, al final de la novela. Vemos así un predominio por una visión estática del personaje que impide definirlo de acuerdo a las funciones (actos). Afirma Leopoldo Marechal: "El argumento de la obra es invisible casi: un puñado de hombres que se mueven y luchan en un escenario grandioso. ¿Para qué luchan y se mueven? No hay allí grandes resortes individuales en juego: los intereses inmediatos (ya sean los del resero, ya los del patrón) no gravitan en la obra. Diríase que los paisanos de Güiraldes, al moverse, trabajar y sufrir, sólo persiguen la realización de un 'gesto' ",.15

¿Cómo se refleja este estatismo en la narrativa? Cada uno de los capítulos nos muestra verdaderos cuadros descriptivos completos. Podemos entonces pasar a denominar las secuencias:

1. Encuentro (caps. I a III)

I. Infancia y adolescencia II. Encuentro con Don Segundo III. Fuga

2. Aprendizaje (caps. IV a XXIV)

IV. Doma V. y VI. Arreo VII. Parada en la pulpería/Caída del caballo VIII. Parada en la estancia/siesta/continuación/llegada. IX. Doma con ayuda de Don Segundo X. Evocación del pasado. XI. Baile XII. Historia de Dolores y Consuelo XIII. Riña de gallos XIV. Feria y continuación del arreo XV. Visión del cangrejal XVI. Rodeo XVII. Matanza del toro XVIII. Convalescencia XIX. Reto amoroso y retirada XX. Carrera de caballos XXI. Historia de Miseria XXII. Doma XXIII. Duelo XXIV. Arreo/Tormenta.

\section{Separación (caps. XXVI a XXVII)}

XXV. Herencia XXVI. Regreso XXVII. Separación

De los veintisiete capítulos, veintiuno están dedicados exclusivamente a una visión enriquecedora de los atributos, ya que el universo del gaucho es descripto en detalle, cediendo un mínimo de espacio narrativo para las acciones, $y$ habiendo en consecuencia un predominio del estatismo de los personajes.

La dificultad de captar el espacio del héroe (de dónde viene y para dónde se dirige), se refleja también en el tiempo de la novela. La localización temporal no obedece a una secuencia cronológica de acuerdo a las acciones, y el tiempo aparece encajado en la narrativa, sirviendo apenas como punto de referencia en ios tres momentos sintetizados en el último capítulo:

1. A orillas de un arroyo resumí antaño mi niñez (p. 182)

(remite al cap. I)

${ }^{15}$ Leopoldo Marechal, art. cit., p. 78. 
2. Dando de beber a mi caballo en la picada de un rio, revisé cinco años de andanzas gauchas (p. 182)

(remite al cap. X)

3. Por último, sentado sobre la pequeña barraca de una laguna, en mis posesiones, consultaba mentalmente mi diario de patrón (p. 182)

(remite al momento presente, cap. XXVII)

Son tres momentos de evocación que remiten al pasado del héroe ${ }^{16 i}$ y que sirven solamente para localizarlo en el tiempo, sin otorgarle ninguna dimensión histórica. Como afirma Noé Jitrik, "es un tiempo abstracto, un tiempo espiritual en la medida en que es despojado de tensiones, alejado e idealizado..." adelante define a Don Segundo como "un ser incontaminado por la historia". El tiempo mítico huye también a una causalidad cronológica: es un tiempo suspendido, estático y circular.

En contraste con este estatismo, encontramos dos momentos en la obra que nos permiten elaborar un análisis de las acciones: son los relatos de los capítulos XII y XXI que representan verdaderas narrativas del folklore argentino, y que pueden ser destacados totalmente de la obra, sin prejuicio de la misma. Son dos casos de narrativa dentro de la narrativa, pero que no se constituyen en ningún sistema metalingüístico: no critican, no resumen ni espejan la obra; sólo la enriquecen a modo de la tradición oral. Como enunciados de acción se oponen a los enunciados descriptivos que dominan la obra, pero, al cabo, hay que admitir que tales narrativas no alteran la "historia".

\section{DSS: “UN LENGUAJE DIVIDIDO}

Si hacemos una lectura del estilo de $D S S$, encontramos de inmediato una notable diferencia en el registro del lenguaje, provocando una escisión lingüística que se manifiesta en dos niveles:

a. lenguaje del narrador (a través del estilo indirecto - "telling")

b. lenguaje del personaje (que se concretiza en el estilo directo, o sea, en los diálogos - "showing")

El primero pertenece al mundo de la narración, mientras el segundo refleja el habla de los participantes de este universo. Veremos cómo las diferencias entre uno y otro estilo nos pueden conducir a conclusiones que, ultrapasando el mero fenómeno lingüístico, se proyectan en lo social y como consecuencia última, en lo ideológico de la obra.

\footnotetext{
${ }^{16}$ Emir Rodríguez Monegal, en conferencia pronunciada en la Universidad de Sao Paulo, (septiembre de 1975), observa que la novela es un 'bildungsroman' que se define como una evocación del tiempo perdido, donde la metáfora del agua(espejo)("arroyo", "rio", "laguna") sirve comoíndice de la introspección del héroe. Este aspecto narcisista apuntado por el crítico, remite no sólo a la relación héroe/historia, sino también al vínculo indisociable narrador/autor, como veremos más adelante.

${ }^{17}$ Noé Jitrik y Adolfo Prieto, (En Capítulo, Buenos Aires,'no, 30, p. 716).
} 
Tomemos un primer ejemplo, contrastando el lenguaje culto del narrador con el habla de los gauchos:

(diálogo) -Valerio te dirá si te quiere yevar.

(narración) Valerio, de quien menos esperaba yo comedimiento, me dijo que hablaría con el patrón, pidiéndole permiso para agregarme a los troperos por medio pago.

(diálogo) - Mirá-agregó-que el oficio es duro.

- No le hace.

- Güeno, esta noche te vi'a contestar.

(p..36, lo subrayado es mío)

La paradoja no reside en la distancia establecida entre el narrador y el personaje, como consecuencia de la diferencia lingüística, sino que quien narra asume concomitantemente el papel de protagonista/narrador, que en última instancia debería estar en una relación de igualdad con su propio desempeño del habla. Es incongruente pensar con un cierto registro del habla (estilo) y hablar con otro. Hay una nítida dicotomía entre uno y otro, denominado "estilo ezquizofrénico" por Antonio Candido.

Delante de esta disyuntiva, hay dos alternativas posibles: o el narrador asimila el lenguaje real del personaje, en un trabajo de conciliación con la cultura a ser retratada, o el personaje opta por hablar en una sintaxis culta, alejándolo así totalmente de su realidad lingüística. Amado Alonso, que se percató de estos dos niveles de los registros del habla, ha osado afirmar:

la afortunada innovación estilística de Güiraldes (...) consiste pues, en haber elaborado literariamente la lengua viva de los provincianos cultos en vez de agauchar la lengua literaria general (...) en vez de partir de la lengua literaria y deformarla hasta vestirla de gaucho, partió de la lengua de los paisanos-o mejor, estancieros cultivados-y la pulió y dignificó hasta darle categoría artística.

Si así fuese, deberíamos emprender la tarea de reescribir Pedro Páramo y Grande Sertão: Veredas, para "elevar" la lengua de los narradores y así "darles categoría artística" a estas obras, cuya proeza fue justamente la eliminación del narrador culto.

En varios momentos notamos el esfuerzo de Güiraldes por integrar a su material narrativo una terminología y modismos del campo:

No hay taba sin culo ni rodeo sin golpeados. Un paisano que me había llamado la atención por su fisonomía taimada, tomó una vaca al cruce y

${ }^{18}$ A mado Alonso, "Un problema estilístico en Don Segundo Sombra" (En Materia y forma en poesia (Madrid: Gredos, ’ 1969, pp. 360-361).

${ }^{19}$ Para un estudio sobre la anulación de distancias entre narrador/personaje/lector, consultar Irlemar Chiampi Cortez, "Narração e metalinguagem em Grande Sertão: Veredas" (En Lingua $e$ Literatura, Revista da FFLCH da Universidade de São Paulo, no. 2, 1973, pp. 63-91). 
la raboneó. No tuvo tiempo de zafarse; su zaino patas blancas se pialó en los garrones de la vaca y cayó como planazo sobre el costillar izquierdo.

(p. 112 , lo subrayado es mio)

Pero advertimos que en ningún caso la pulcritud del lenguaje sufre cualquier tipo de modificación. Jamás en la narración, por más que quiera acercar el lenguaje gaucho al suyo, va a escribir "llama'o" por "llamado". En ningún momento abdica en su narración de la sintaxis purista, lo que implica nítidas consecuencias sociolingüísticas: si el lenguaje de la narración no corresponde al lenguaje gaucho-como es demostrado en los diálogos-quien narra no se personifica o identifica, al narrar, como gaucho. Por el contrario, el cuidado en mantener intacta la sintaxis normativa, hace que cada vez más notemos la presencia culta y elitista del narrador.

El binomio sociolingüístico se instaura de la siguiente manera:
a. diálogo: personaje
b. narración:
gaucho (Don Segundo,
Fabio Cáceres, etc.)
personaje/narrador Fabio Cáceres desen- mascarado por el len- guaje del autor $\mathrm{Ri}-$ cardo Güiraldes.

Esta polarización provoca constantemente un alejamiento del personaje. No conseguimos integrarlo, ya que la diferencia en el registro del habla nos muestra una diferencia social latente. Esta misma distancia que el autor/narrador asume con relación a su propio personaje se proyecta en la relación lector/personaje. Pasamos a ver al personaje como una entidad folklórica, pintoresca. Antonio Candido describe, de manera brillante, un fenómeno análogo en las letras brasileñas:

En realidad, al narrador o al personaje cultos, de clase superior, le es reservada la integridad del discurso, que traduce por la grafía convencional, indicadora de la norma culta. En los libros regionalistas, el hombre de posición social más elevada nunca tiene acento, no presenta peculiaridades de pronunciación, no deforma las palabras que, en su boca, asumen el estado ideal del diccionario. Cuando, al contrario, marca el desvío de la norma en el hombre rural pobre, el escritor da al nivel fónico un aspecto casi teratológico, que confamina todo el discurso y localiza al emisor como un ser aparte, un espectáculo pintoresco como los árboles y los animales, hecho para contemplación o diversión del hombre culto, que de esta manera se siente confirmado en su superioridad. En tales casos, el regionalismo es una falsa admisión del hombre rural al universo de los valores ético y estéticos. ${ }^{20}$

\footnotetext{
${ }^{20}$ Antonio Candido, "A literatura e a formação do homem' (En revista Ciência e Cultura, no. 24(9), setembro 1972, p. 808). (La traducción es mía).
} 
Pasamos entonces a ver al personaje más como un fenómeno lingüístico que como una realidad ficcional a la cual debemos integrarnos.

Durante los diálogos, el habla del personaje disfraza momentáneamente la influencia del autor. Consecuentemente, la relación se presenta objetivamente

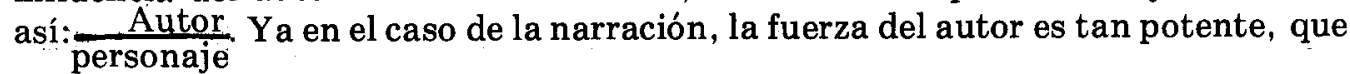
contamina al narrador/personaje anulándolo: Autor

\section{narrador personaje}

Otros ejemplos del lenguaje culto usado por el narrador: "Don Segundo, que al lado mío, ya alcanzándome alguna pilcha, ya apadrinándome, me guiaba paso a paso, sapientemente." (p. 154, lo subrayado es mío). Los juicios que Fabio Cáceres emite sobre sí mismo son demasiado lúcidos; parecen ser expresados por un narrador oculto, o en última instancia, conlleva la interferencia del propio autor. Este fenómeno es común en DSS:

Pago es patria chica, $y$, por más que nos independicemos, nos quedan metidas dentro cuñas de goce o de dolor, ya hechas carne con el tiempo.

Me sentía bien a pesar de mi crisis moral. Tenía una extraña sensación de existencia nueva. (p. 179)

¿Cómo mirar para atrás ni valorar pasados, cuando el presente siempre me obligaba a una continua acción atenta? (p. 181)

Vemos cómo la omnisciencia "autoral" se patentiza cada vez más a través del narrador, y no sólo del supuesto personaje, que es usado como títere del ventrílocuo. Y si en algún momento el narrador trata de nivelar el abismo lingüístico, fundiendo a su lenguaje narrativo el lenguaje gaucho, en ningún momento la integración de un lenguaje en el otro implica una ruptura de estilo:

Ya está tomada la actitud, y no queda más que hacer "pata ancha" (...)

Cómo hablaría, en efecto, cuando, "el recao me dentrara a lonjiar las nalgas" (...) ¿Para qué diablos me sacaron del lado de "mama"? (p. 41)

Gracias a las comillas que aparecen en el texto, el narrador no permite la interferencia del lenguaje que viene "desde abajo". Retomando la metáfora de Paul Groussac, es como si entre el chiripá y el smocking el narrador usase un impermeable, para garantizar que no hay ninguna contaminación entre los dos niveles. Así, el universo lingüístico culto y elitista, cristalizado por las normas académicas, se mantiene intacto $\mathrm{y}$ aislado.

\subsection{La Escisión Sociolingüistica}

En este momento debemos ir en contra de las normas del análisis literario inmanente, y hablar del autor: Ricardo Güiraldes. Es pertinente subrayar nuevamente que Güiraldes perteneció a la aristocracia terrateniente argentina. S’ visión es "desde arriba" y esto se concretiza a través de su lenguaje. 
Güiraldes conoce profundamente el campo: vivió en él, pero conoce también la distancia geográfica, ya que vivió buena parte de su vida en París y en viajes por el Oriente. Su posición elitista no se basa tanto en el hecho de pertenecer a una clase económicamente privilegiada; él pertenece a una élite cultural: la de los productores y consumidores de arte..$^{21}$ Ricardo Güiraldes se torna representante de una élite que pasa a valorizar aspectos regionalistas del Nuevo Continente; pero es una visión americanista equivocada, "raffiné", y no integratoria, como había idealizado Bolívar. Sólo más tarde, en la ficción de Rulfo y Guimarães Rosa habrá una verdadera fusión de culturas, ya al nivel del lenguaje.

Tenemos así dimensionado al autor en el contexto social de su época, como causa y explicación de la escisión lingüística presente en la obra. Este fenómeno no es aislado ni peculiar a DSS; es un problema típico de su época, y hasta en la literatura brasileña lo encontramos nitidamente reflejado en la obra de João Simões Lopes Neto (1865-1916), como lo muestra el análisis de Antonio Candido. El problema es tan caracterizable, que Ängel Rama observa:

Las novelas de este regionalismo establecían un curioso escalón entre el personaje que hablaba en un particular galimatías criollista, y el autor, quien se situaba por encima de sus criaturas y al describir, al comentar, al narrar, hablaba desde su cátedra más o menos purista. En los hechos asistíamos a una intensificación del diocesillo escritor que habían engendrado los naturalistas del siglo pasado, pues ese autor manejaba a sus criaturas como a los integrantes de su zoológico particular y los ponía a hacer las correspondientes pruebas circenses. (op. cit., p. 47)

Una prueba contundente en DSS de esta diferencia sociolingüística, la encontramos en dos momentos:

(narra Fabio Cáceres)

(...) cerca mío, un grupo de gente rica, bien montada, hablaba de las carreras depositadas. El que parecía más al corriente que los demás explicaba:

(diálogo)

- Yo no sé como Silvano se ha metido a correr con el mano blanca de los de Acuña; su alazancito es un animal nuevo, muy bruto. Ustedes verán que es capaz de asustarse con la gente y cambiar de andarivel.

$$
\text { (p. 140 - lo subrayado es mío) }
$$

La pulcritud del lenguaje, la pronunciación sin contracciones ni distorsiones, hace que éste coincida con el estrato social indiciado por el mismo narrador: "gente rica". En otro momento, este mismo fenómeno aparece de manera más evidente, de modo más contrastado: (Fabio Cáceres, reproduciendo a modo de narración, el habla de Don Segundo, al comentar la matanza del negro del cap. XXIII):

${ }^{121}$ Cf. Angel Rama, Diez problemas para el narrador latinoamericano, (Venezuela: Ed. Síntesis Dosmil, 1972). 
-Yo-dijo mi padrino-he tenido más de muchas de estas diferencias con hombres que eran o se craiban malos y nunca me han cortao (...) ni tampoco he muerto a naide, porque no he hallao necesidá. Con todo, el mocito que se ha desgraciao no lleva culpa. La pelea, en qüena ley y asigún el mesmo desafío del finao, debió concluir donde lo cortaron.

(p. 164 - lo subrayado es mío)

y comentando la muerte del mismo personaje, añade un médico:

- iQué puñalada! Cuando yo era practicante, y no fui débil, sudaba media hora para abrir así un tórax. (p. 164)

La perfección lingüística se contrapone al lenguaje del gaucho, y los dos lenguajes adquieren características sociales diferenciadas y perfectamente categorizables. En estos ejemplos la escisión lingüística y social es radical, además de correr de manera paralela.

Podemos atinar a una prinera conclusión, afirmando que el autor ejerce una función de dominio sobre la narrativa, al nivel del propio lenguaje. Existe una relación de subordinación por parte del personaje cuando éste, en vez de adquirir un lenguaje propio (como sería el caso de Martín Fierro) sirve de portavoz del pensamiento del autor. Así, el personaje, en vez de adquirir autonomía como tal, no pasa de una extensión de la voz del autor, haciendo que la obra tenga repercusiones de cuño ideológico.

\section{DSS: UNA ESTETICA Y UNA IDEOLOGIA MONOLOGICAS}

La ideología del autor no entra en choque en ningún momento con la de sus personajes; por el contrario, gracias a su profunda intromisión consigue hacer del material narrado una proyección de sí mismo. Así el autor disfraza su personalidad en un proceso reductivo del personaje a persona (máscara). El narrador/autor no establece un diálogo con su personaje; en el sentido de oposición de ideas. El carácter descriptivo del héroe y su ambiente en DSS hace que el autor se refiera a su personaje, sin establecer un diálogo con el mismo; en última instancia es un verdadero monólogo. No surgen oposiciones ni en la relación autor/personaje, ni en la relación personaje/personaje, y menos aún una oposicion entre el personaje y su autor. En realidad, Ricardo Güiraldes no da autonomía a ninguno de sus personajes, ya que ellos están ideológicamente predeterminados por la ideología del mismo autor.

Mikhail Bakthine, ${ }^{23}$ crítico ruso posformalista, cuya obra figura entre las más fecundas de la crítica literaria contemporánea, describe la novela monológica

\footnotetext{
${ }^{22}$ No puedo, en este momento, dejar de establecer una analogía del contenido ideológico de la obra con su título: Don Segundo Sombra. En la vasta bibliografía existente, pocos han resistido a la tentación de analizar el enigmático título: ¿por qué "Sombra"? Las explicaciones más verosímiles son aquéllas que muestran la relación "Sombra/ser idealizado". De cualquier modo, la voluntariedad de Ricardo Güiraldes en relación a la manipulación "autoral" del texto, le otorga al autor un lugar de primacía, convirtiendo, en consecuencia, al desempeño narrativo del héroe en $s u$ "Segundo" y, metafóricamente, su propia "sombra".

${ }^{i 23}$ Mikhail Bakthine, La poétique de Dostoievski (Paris: Seuil, 1970). (Original ruso de 1929; la traducción del francés es mía).
} 
(p.ej. la de Tolstoi), como "un mundo objetivo, único o igual, visto y representado a partir del único punto de vista del autor" y donde "la palabra del héroe está aprisionada dentro del cuadro rígido de las palạbras del autor" (p. 93). La relación entre el autor, el narrador, y los personajes es de total identidad, de coincidencias ideológicas. Ricardo Güiraldes, así como Tolstoi, "habla del héroe, $\mathrm{y}$ no con el héroe. La última palabra pertenece al autor, $\mathrm{y}$, basándose en el hecho de que el héroe no ve, no comprende aquello que le es exterior a su consciencia, no puede jamás encontrar la palabra del héroe sobre un mismo plano dialógico" (p. 111).

En contraposición al personaje monológico, el héroe de la novela polifónica (Raskolnikov, Don Quijote, etc.) "goza de una autoridad ideológica y una independencia perfecta; es reconocido como autor de sus propias concepciones ideológicas de valor absoluto, y no como objeto de la visión artística del autor" (p. 31). Encontramos así, en la novela polifónica varios universos ideológicos dentro de un mismo texto, como en Dostolevski, donde existen personajes que se oponen a la ideología del propio autor. Los personajes de la novela polifónica asumęn así sus propios discursos, y no son vehículos del discurso del autor, como Don Segundo. Comparando:

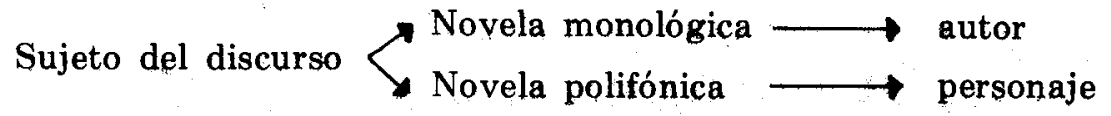

La visión idealizada del gaucho, encarnada en la figura de Don Segundo, se proyecta sobre Fabio Cáceres, cuyo ideal es llegar a ser como Don Segundo (a esta altura es irónica la paradoja, pues Fabio Cáceres, adulto, está totalmente distanciado de la imagen mítica inicial de Don Segundo, que él se había propuesto imitar) y en ningún momento los personajes se oponen, pues ellos son totalmente dependientes de la visión del mundo de Ricardo Güiraldes. La proyección autor/personaje diluye cualquier posibilidad de independencia ideológica del mismo; estas ideologías se convierten en lo que Bakthine llama de "conciencias" o "voces narrativas". En DSS hay una única conciencia o una única voz narrativa: la de Ricardo Güiraldes, y las consecuencias inmediatas de este acto de posesión del lenguaje, residen on una visión monolítica, unilateral y parcial del mundo descripto por el autor. Si la novela polifónica condensa varias "voces", haciendo que las diversas ideologías entren en choque en el corpus narrativo, ya $D S S$ es un vivo ejemplo de uno novela monofónica.

En lo que se refiere a la relación autor/personaje, Güiraldes deja muy claro lo que el gaucho representa en su mundo (lo dice de manera explícita en la dedicatoria), y en ningún momento se vislumbra lo que el mundo puede significar para el personaje (como sucede en Martín Fierro), ya que éste posee una visión filtrada por la ideología del autor.

En la novela polifónica los elementos más opuestos pueden suceder al mismo tiempo, ya que las oposiciones no representan contradicciones, pues conviven a 
través de una lógica de heterogeneidad. La simultaneidad y concomitancia se oponen a la lógica lineal y sucesiva del monologismo que, como en DSS, se convierten en un suceder automatizado de las acciones: "la novela monológica es mecánica desde el punto de vista de su mundo monolítico, unilateral, y cuyo código se hace previsible, en la medida en que no hay "voces" que la constrasten o se le opongan", afirma Bakthine (p. 77). Ya en la novela polifónica el personaje difícilmente está de acuerdo consigo mismo, como condición de superación de su propio yo. Un yo en continuo cambio y evolución que se sobrepone a sí mismo a todo momento en una perspectiva múltiple de personalidad que nos da una visión dialógica de la misma.

Para que el héroe consiga mantener el monologismo, desde el comienzo hasta el final de la obra, es necesario que sea postulada una ideología exterior y anterior a la novela, como explicación de su inmutabilidad. La creación de ideologías no se produce entonces dentro de un proceso de dialéctica interna de la obra, donde los diversos puntos de vista, o "voces", o "conciencias" entran en choque.

Comparando y resumiendo: en la visión polifacética del mundo encontramos la pluralidad de conciencias, donde

Sujeto es el personaje

Objeto es la ideología del personaje.

En la visión monolítica del mundo hay una única "voz", donde

Sujeto es el autor

Objeto es el personaje

Tenemos así como sujeto a Ricardo Güiraldes y como objetos a Don Segundo y Fabio Cáceres. El lenguaje en DSS puede manifestarse de manera distinta y través de los discursos directos e indirectos, pero la ideología subyacente es siempre una sola: una verdadera traducción monológica del mundo enmascarada por dos estilos diferentes: el del chiripá y el del smocking.

Concluyendo, vemos como la narración garantiza la posesión [la propiedad] del autor sobre su materia y sobre el lector, así como la fábula garantiza la heredad de Fabio Cáceres. Personaje y autor se encaminan mano a mano hacia la posesión, conduciendo y "cerrando" el universo de DSS, en la glorificación de la ideología capitalista. La visión burguesa de la seguridad material surge a través de la consagración de la propiedad, del bienestar y del disfrute apacible de las bellas letras en la vejez de Fabio Cáceres. Es el ensalzamiento de la persepectiva omnisciente, todopoderosa, monovalente, estática y anti-dialógica.

$D S S$ es la novela epigonal del periodo regionalista, el canto del cisne de una literatura cerrada y elitista, que no cuestiona las complejas realidades latinoamericanas. Es una novela-modelo, de una época y un pensamiento contra los cuales los nuevos creadores de la década del 40 se van a rebelar. 